\title{
Tumor lysis syndrome in the emergency department: challenges and solutions
}

\author{
This article was published in the following Dove Press journal: \\ Open Access Emergency Medicine \\ 20 August 2015 \\ Number of times this article has been viewed
}

\author{
Silvio A Ñamendys-Silva ${ }^{1,2}$ \\ Juan MArredondo- \\ Armenta' \\ Erika P Plata-Menchaca ${ }^{2}$ \\ Humberto Guevara-García' \\ Francisco J García-Guillén' \\ Eduardo Rivero-Sigarroa ${ }^{2}$ \\ Angel Herrera-Gómez' \\ 'Department of Critical Care \\ Medicine, Instituto Nacional de \\ Cancerología, ${ }^{2}$ Department of Critical \\ Care Medicine, Instituto Nacional de \\ Ciencias Médicas y Nutrición Salvador \\ Zubirán, Mexico City, Mexico
}

Correspondence: Silvio A Ñamendys-Silva Department of Critical Care Medicine, Instituto Nacional de Cancerología, Av San Fernando No 22, Col Sección XVI, Delegación Tlalpan, CP 14080 México City, DF, México Tel +52 554747 I020 ext I30I5, I3016 Email snamendys@incan.edu.mx

\begin{abstract}
Tumor lysis syndrome (TLS) is the most common oncologic emergency. It is caused by rapid tumor cell destruction and the resulting nucleic acid degradation during or days after initiation of cytotoxic therapy. Also, a spontaneous form exists. The metabolic abnormalities associated with this syndrome include hyperkalemia, hyperphosphatemia, hypocalcemia, hyperuricemia, and acute kidney injury. These abnormalities can lead to life-threatening complications, such as heart rhythm abnormalities and neurologic manifestations. The emergency management of overt TLS involves proper fluid resuscitation with crystalloids in order to improve the intravascular volume and the urinary output and to increase the renal excretion of potassium, phosphorus, and uric acid. With this therapeutic strategy, prevention of calcium phosphate and uric acid crystal deposition within renal tubules is achieved. Other measures in the management of overt TLS are prescription of hypouricemic agents, renal replacement therapy, and correction of electrolyte imbalances. Hyperkalemia should be treated quickly and aggressively as its presence is the most hazardous acute complication that can cause sudden death from cardiac arrhythmias. Treatment of hypocalcemia is reserved for patients with electrocardiographic changes or symptoms of neuromuscular irritability. In patients who are refractory to medical management of electrolyte abnormalities or with severe cardiac and neurologic manifestations, early dialysis is recommended.
\end{abstract}

Keywords: tumor lysis syndrome, emergency department, emergency management, intensive care, oncologic emergency

\section{Introduction}

Tumor lysis syndrome (TLS) represents the most frequent oncologic emergency, caused by lysis of tumor cells and output of large amounts of potassium, phosphate, and nucleic acid. It was described in 1929 by Bedrna and Polcák. This syndrome occurs mainly after initiation of cytotoxic therapy in patients with lymphoma and leukemia, but it can also occur spontaneously in malignancies with a large tumor burden. ${ }^{1-3}$ TLS produces serious and potentially lethal consequences, which affect mainly the electrolyte metabolism and renal parenchyma. The most common ionic abnormalities associated with TLS include hyperkalemia, hyperphosphatemia, and hypocalcemia. TLS-associated acute kidney injury (AKI) is caused by multiple factors, including the tubular deposition of uric acid crystals and calcium phosphate and changes in renal blood perfusion. The emergency department (ED) management strategy for overt TLS is proper fluid resuscitation, use of hypouricemic agents, use of renal replacement therapy, and correction of electrolyte imbalance. ${ }^{4}$

Allantoin is a nontoxic substance, more soluble than uric acid and of easier metabolism and renal excretion. Rasburicase promotes catabolism of uric acid to allantoin 
molecule, being useful for primary prophylaxis in high-risk patients. Allopurinol is an alternative option for prophylaxis in high-risk patients, although its efficacy is less clear. ${ }^{5-7}$

\section{Definition}

There is no universal TLS definition, but Cairo and Bishop's laboratory and clinical criteria are commonly used for the diagnosis. For diagnosis of biochemical TLS, two or more of the following criteria occur simultaneously within 3 days before or up to 7 days after initiation of chemotherapy: hyperuricemia (increase in uric acid of $25 \%$ from baseline or uric acid $>8 \mathrm{mg} / \mathrm{dL}$ ), hyperkalemia (increase in potassium of $25 \%$ from baseline or potassium $>6 \mathrm{mEq} / \mathrm{L}$ ), hyperphosphatemia (increase in phosphorus of $25 \%$ from baseline or phosphorus $>5 \mathrm{mg} / \mathrm{dL}$ ), and hypocalcemia (reduction in serum calcium of $25 \%$ from baseline or corrected serum calcium $<7 \mathrm{mg} / \mathrm{L}$ or ionized calcium $>1.12[0.3 \mathrm{mmol} / \mathrm{L}]$ ). The clinical TLS is present when laboratory abnormalities are associated with AKI (increase in serum creatinine $>1.5$ times the baseline level), seizures, heart rhythm abnormalities, or death. These criteria are not useful for diagnosis of spontaneous TLS. ${ }^{8-11}$

\section{Epidemiology}

The incidence varies greatly depending on the underlying malignancy. The major risks for TLS are related to those neoplasms that have a high volume and a high metabolism rate, such as B-cell acute lymphoblastic leukemia and Burkitt's lymphoma. The lowest risk for TLS occurs in solid tumors or hematological malignancies with slow growth rate (such as multiple myeloma). ${ }^{10-17}$

\section{Pathophysiology}

TLS develops when there is a rapid degradation of the nucleic acids caused by tumor cell destruction, during the administration of chemotherapy or within 7 days after initiation of cytotoxic therapy, resulting in characteristic electrolyte disturbances. All these abnormalities can lead to fatal consequences. Two relevant complications are lifethreatening arrhythmias (due to electrolyte imbalances) and AKI (due to hyperuricemia or hyperphosphatemia).

Hyperkalemia can result from two different mechanisms. First, the presence of a gradient of potassium across the cell membrane that is regulated by the sodium-potassium adenosine triphosphatase (ATPase). Any interruption in its operation can lead to a potassium efflux into the bloodstream. When chemotherapy or radiotherapy is initiated, there is an increase in cellular metabolism and adenosine triphosphate
(ATP) is consumed at a higher rate. Consequently, there is little remaining ATP to maintain the potassium gradient. Therefore, potassium leaves the cell even before the lysis of neoplastic cells. ${ }^{18}$ The second mechanism is the release of intracellular potassium stores in the blood after lysis of tumor cells. Hyperkalemia is typically seen 12-24 hours after therapy and therefore is the initial life-threatening consequence of TLS. ${ }^{19}$ Hypocalcemia is secondary to the release of phosphate from lysed cells. Hematologic malignant cells contain up to four times more intracellular phosphate than normal lymphoid cells. Significant elevations in phosphorus blood measurements are not seen until blood levels exceed the capacity for renal excretion of phosphate. This usually occurs 24-48 hours after initiation of therapy. Hypocalcemia can lead to not only tetany and seizures but also fatal cardiac arrhythmias.

Hyperuricemia usually develops 48-72 hours after initiation of chemotherapy. Nucleic acids are released into the blood after cell lysis and are converted to uric acid by xanthine oxidase. Under normal circumstances, they are recycled by purine salvage pathways to minimize excretion. However, in TLS, the mechanisms of recovery of remaining cells are exceeded, and there is an increase of uric acid passage and secretion by the renal tubule, leading to renal failure. ${ }^{20-22}$

\section{AKI mechanisms}

There are several potential mechanisms for AKI in patients with TLS. The depletion of intravascular volume may create an incentive for the reabsorption of uric acid and subsequent net secretion in the distal tubules. The presence of low urinary $\mathrm{pH}$ promotes the precipitation of uric acid in the renal collecting system and distal tubules, which leads to uric acid nephropathy and oliguric AKI. ${ }^{22,23}$

TLS-associated hyperphosphatemia can also contribute to AKI. Precipitation of calcium phosphate in the renal tubule is the main mechanism involved. Another possible mechanism that contributes to AKI is renal vasoconstriction, caused by the release of adenosine to the bloodstream after lysis of tumor cells. ${ }^{24}$ TLS-associated AKI has several consequences that may contribute to rapid clinical deterioration of the patient. Oliguria can lead to volume overload, secondary hypertension, and pulmonary edema. High levels of blood urea nitrogen (BUN) may be severe enough to cause pericarditis and platelet dysfunction. ${ }^{7}$ Anion gap metabolic acidosis is the main acid base abnormality, and it can worsen electrolyte imbalances. Early and aggressive treatment of AKI is vital to avoid or at least minimize these complications. ${ }^{22,24,25}$ 


\section{Risk stratification}

An expert panel has proposed risk stratification criteria for patients who are prone to develop TLS, to guide the acute management of complications (Table 1). High-risk patients are those who have $>5 \%$ risk of developing TLS. ${ }^{26}$

In keeping with the recommendations of the expert panel, it is recommended that all patients who fit into these high-risk categories receive aggressive IV hydration and prophylactic rasburicase rather than allopurinol prior to treatment initiation (unless they have glucose-6-phosphate dehydrogenase deficiency). ${ }^{26}$

\section{Treatment}

TLS is an emergency and life-threatening clinical condition most commonly encountered by oncologists, ED physicians, and critical care teams, in which clinical consequences are derived from metabolic abnormalities that it creates. ${ }^{10,27,28}$ At the ED, it is crucial to diagnose and stratify the risk for TLS before initiating treatment in a timely manner, avoiding taking measures once overt TLS has developed and the preventive measures are no longer beneficial.

\section{Hydration}

In the management of overt TLS, efforts should be made to restore normal concentrations of extracellular solutes. Providing complete loss of kidney function has not been established, volume expansion is useful in order to increase renal solute excretion. Besides increasing the excretion of potassium, phosphorus, and uric acid, it maintains adequate urinary volumes and diminishes precipitation of calcium phosphate crystals in renal tubules. ${ }^{28-32}$

Intravenous administration of fluids is recommended with $2-3 \mathrm{~L} / \mathrm{m}^{2} /$ day in order to maintain diuresis in a range of $100-200 \mathrm{~mL} / \mathrm{h}$ in adult patients without contraindication for volume expansion, as in the case of patients with heart failure. Ideally, IV hydration in high-risk patients should begin 24-48 hours prior to initiation of cancer therapy and may be continued for 48-72 hours after completion of chemotherapy. Diuretics can be used to maintain adequate urinary volumes only after correcting hypovolemia. ${ }^{33}$

\section{Hyperuricemia}

Allopurinol is a structural analog of the purine base hypoxanthine and acts as an inhibitor of xanthine oxidase, the enzyme responsible for the conversion of hypoxanthine to xanthine and xanthine to uric acid. Allopurinol treatment can increase serum and urine levels of xanthine, a sparingly soluble substance that can lead to the formation of crystals in the renal tubules, worsening the glomerular filtration rate. As such, it has an advantageous role for prophylaxis of high-risk patients but may be less effective than rasburicase as a treatment choice. The usual allopurinol dose in adults is $100 \mathrm{mg} / \mathrm{m}^{2}$ every 8 hours (maximum $800 \mathrm{mg} /$ day). ${ }^{34}$

Allopurinol has been associated with several hypersensitivity syndromes, especially in patients with compromised renal function. . $^{11,22,34-36}$

Rasburicase is an enzyme that metabolizes uric acid to allantoin, which is more soluble and removable by the kidneys than xanthine. This agent is not only useful for TLS prevention but also indicated for treatment. Currently, the recommended dose is $0.15-0.2 \mathrm{mg} / \mathrm{kg} /$ day in $50 \mathrm{~mL}$ of sodium chloride $0.9 \%$ in infusion for 30 minutes once a day; the average duration of therapy is 2 days, but can range from 1 day to 7 days. Rasburicase should be avoided in patients with deficiency of glucose-6-phosphate dehydrogenase as it may cause hemolysis..$^{22,37-39}$

Table I Risk stratification in patients prone to developing tumor lysis syndrome

\begin{tabular}{|c|c|c|c|}
\hline Type of cancer & High & Intermediate & Low \\
\hline \multicolumn{4}{|l|}{ Patient stratification by risk } \\
\hline $\mathrm{NHL}$ & $\begin{array}{l}\text { Burkitt's, lymphoblastic } \\
\text { B-cell acute lymphoid } \\
\text { leukemia }\end{array}$ & $\begin{array}{l}\text { Diffuse large B-cell } \\
\text { lymphoma }\end{array}$ & Indolent NHL \\
\hline Acute lymphoid leukemia & WBCC $\geq 100 \times 10^{9} / \mathrm{L}$ & WBCC $\geq 50-100 \times 10^{9} / \mathrm{L}$ & $\mathrm{WBCC} \leq 50 \times 10^{9} / \mathrm{L}$ \\
\hline Acute myeloid leukemia & $\begin{array}{l}\mathrm{WBCC} \geq 50 \times 10^{9} / \mathrm{L} \\
\text { monoblastic }\end{array}$ & WBCC $10-50 \times 10^{9} / \mathrm{L}$ & WBCC $\leq 10 \times 10^{9} / \mathrm{L}$ \\
\hline Chronic lymphocytic leukemia & & $\begin{array}{l}\text { WBCC } 10-100 \times 10^{9} / \mathrm{L} \\
\text { Treatment with fludarabine }\end{array}$ & WBCC $\leq 10 \times 10^{9} / \mathrm{L}$ \\
\hline $\begin{array}{l}\text { Other hematologic malignancies } \\
\text { (chronic myeloid leukemia and } \\
\text { multiple myeloma) and solid tumors }\end{array}$ & & $\begin{array}{l}\text { Rapid proliferation with } \\
\text { expected rapid response } \\
\text { to therapy }\end{array}$ & $\begin{array}{l}\text { Remainder of } \\
\text { patients }\end{array}$ \\
\hline
\end{tabular}

Note: Reprinted with permission (C) 2008 American Society of Clinical Oncology. All rights reserved. Coiffier B. et al: J Clin Oncol. 2008;26(I6):2767-2778.26 Abbreviations: NHL, Non-Hodgkin Lymphoma; WBCC, white blood cell count. 


\section{Urine alkalinization}

The solubility of uric acid is highly dependent on the urinary $\mathrm{pH}$. At a urinary $\mathrm{pH}$ of 5.0, the solubility of uric acid is $15 \mathrm{mg} / \mathrm{dL}$, instead of $200 \mathrm{mg} / \mathrm{dL}$ at a urinary $\mathrm{pH}$ of 7.0 . Urinary alkalinization increases the solubility of uric acid but decreases the solubility of phosphate and may favor the precipitation of calcium phosphate salts in soft tissues and renal tubules, potentially worsening renal failure. A more alkaline $\mathrm{pH}$ also decreases levels of ionized calcium perpetuating the existing hypocalcemia and its complications. Because it is harder to correct hyperphosphatemia than hyperuricemia, urinary alkalinization in patients with TLS is controversial and should not be routinely used. Urine alkalinization may be considered in cases when there is no rasburicase available and severe hyperuricemia is present. ${ }^{10,11,40,41}$

\section{Hyperkalemia}

Hyperkalemia is still the most dangerous component of TLS because it can cause sudden death from cardiac arrhythmias. Thus, it should be treated quickly and aggressively. Immediate administration of $50 \mathrm{~mL}$ of $50 \%$ dextrose ( $25 \mathrm{~g}$ of glucose) intravenously with eight units of insulin, IV calcium gluconate, and beta- 2 agonists is recommended. Loop diuretics can be used to promote the excretion of potassium, and calcium gluconate can be used to prevent the risk of arrhythmias. The hyperkalemia that is refractory to medical management should be treated with dialysis. ${ }^{11,22}$

\section{Hyperphosphatemia}

Treatment of hyperphosphatemia is indicated when it is severe, acute, and accompanied by clinical manifestations. The management is based on the volume expansion by providing sodium chloride solution $0.9 \%$ in order to promote renal excretion of phosphorus. Phosphorus chelating solutions (aluminum hydroxide, calcium carbonate) are a possible option, but in the context of AKI, the kidney function replacement is the most effective method for the treatment of this serious complication. ${ }^{4}$

\section{Hypocalcemia}

Hypocalcemia may also threaten the patient's life, by triggering arrhythmias and leading to neuromuscular irritability. Symptomatic hypocalcemia should be treated with the required lowest dose of IV calcium gluconate to alleviate symptoms, since excess calcium administration increases the risk of crystallization of calcium phosphate and accumulation in tissues. Controlling serum phosphorus levels can prevent hypocalcemia. Administration of IV calcium gluconate is reserved for patients with electrocardiographic changes, tetany, and convulsions. ${ }^{10,21}$

\section{Renal replacement therapy}

In patients who develop AKI with associated hyperkalemia, hyperphosphatemia, and hyperuricemia; those who do not respond to medical treatment; or in whom some conditions like heart failure are present and discourage adequate fluid resuscitation, dialysis is indicated. Given the fact that TLS originates from a continuous release of potassium, phosphorus, and uric acid, continuous modes of renal replacement function are preferred to intermittent hemodialysis to reduce the risk of rebound hyperkalemia and hyperphosphatemia. However, potassium excretion is greater with conventional hemodialysis. Additionally, in patients with life-threatening hyperkalemia, starting early hemodialysis followed by continuous renal replacement therapy is recommended to prevent this rebound effect. For hyperphosphatemia management in patients with AKI, continuous replacement therapy is preferred, since phosphorus removal is time dependent. ${ }^{11,42,43}$

\section{Monitoring}

High-risk patients should be continuously monitored and should undergo measurement of serum electrolytes, creatinine, and uric acid every 6 hours after initiation of cytotoxic therapy. For patients with overt TLS, admission to the intensive care unit may be considered. ${ }^{10,42}$

\section{Prognosis}

The prognosis depends on the severity of TLS and electrolyte imbalances. The most severe and often lethal forms of TLS occur in cases with the spontaneous form of the condition. The occurrence of AKI is associated with high mortality rates. Since the incorporation of rasburicase, there has been an improvement in the prognosis of severe forms; however, mortality remains high. ${ }^{42}$

\section{Conclusion}

TLS is an oncologic emergency characterized by the development of hyperuricemia, AKI, and electrolyte disturbances that can be life threatening. It is crucial to identify patients at high risk for this syndrome for prompt detection of those patients with TLS suitable to receive early treatment. ED management implies correct fluid resuscitation, use of hypouricemic agents, instauration of renal replacement therapy, and correction of electrolyte imbalances. 


\section{Disclosure}

The authors report no conflicts of interest in this work.

\section{References}

1. Thapa J, Pandey S, Sitaula S, et al. Spontaneous tumor lysis syndrome - a rare occurrence in endometrial/ovarian carcinoma. Crit Care Med. 2013;41(12 Suppl):A345.

2. Bedrna J, Polcák J. Akuter harnleiterverschluss nach bestrahlung chronischer leukämien mit röntgenstrahlen. Med Klin. 1929;25:1700-1701.

3. Soares M, Caruso P, Silva E, et al; Brazilian Research in Intensive Care Network (BRICNet). Characteristics and outcome of patients with cancer requiring admission to intensive care units: a prospective multicenter study. Crit Care Med. 2010;38(1):9-15.

4. Burghi G, Berrutti D, Manzanares W. Tumor lysis syndrome in intensive care: diagnosis encare and therapeutic. Med Intensiva. 2011;35(3): $170-178$.

5. Pui CH. Rasburicase: a potent uricolytic agent. Expert Opin Pharmacother. 2002;3(4):433-442.

6. Oldfield V, Perry C. Rasburicase. Drugs. 2006;66(4):529-545.

7. Tosi P, Barosi G, Lazzaro C, et al. Consensus conference on the management of tumor lysis syndrome. Haematologica. 2008;93(12): 1877-1885.

8. Cairo MS, Bishop M. Tumour lysis syndrome: new therapeutic strategies and classification. Br J Haematol. 2004;127(1):3-11.

9. Levin A, Warnock DG, Mehta RL, et al; Acute Kidney Injury Network Working Group. Improving outcomes from acute kidney injury: report of an initiative. Am J Kidney Dis. 2007;50(1):1-4.

10. Scott CH, Deborah P, Ching-Hon P. The tumor lysis syndrome. Current concepts. N Engl J Med. 2011;364(19):1844-1854.

11. Perry W, Jeffrey S. Tumor lysis syndrome: new challenges and recent advances. Adv Chronic Kidney Dis. 2014;21(1):18-26.

12. Wössmann W, Schrappe M, Meyer U, Zimmermann M, Reiter A. Incidence of tumor lysis syndrome in children with advanced stage Burkitt's lymphoma/leukemia before and after introduction of prophylactic use of urate oxidase. Ann Hematol. 2003;82(3):160-165.

13. Abu-Alfa AK, Younes A. Tumor lysis syndrome and acute kidney injury: evaluation, prevention, and management. Am J Kidney Dis. 2010 55(5 Suppl 3):1-13.

14. Noh GY, Choe DH, Kim CH, Lee JC. Fatal tumor lysis syndrome during radiotherapy for nonsmall-cell lung cancer. $J$ Clin Oncol. 2008;26(36):6005-6006

15. Sezer O, Vesole DH, Singhal S, et al. Bortezomib-induced tumor lysis syndrome in multiple myeloma. Clin Lymphoma Myeloma. 2006;7(3):233-235.

16. Cairo MS, Coiffier B, Reiter A, Younes A; TLS Expert Panel. Recommendations for the evaluation of risk and prophylaxis of tumour lysis syndrome (TLS) in adults and children with malignant diseases: an expert TLS panel consensus. Br J Haematol. 2010;149(4): 578-586.

17. Natasha K, Bojana D, Claire T. Spontaneous tumour lysis syndrome CMAJ. 2012;184(8):913-916.

18. Chasty R, Liu-Yin J. Acute tumour lysis syndrome. Br J Hosp Med. 1993;49(7):488-492.

19. Flombaum C. Metabolic emergencies in the cancer patient. Semin Oncol. 2000;27(3):322-334

20. Yarpuzlu AA. A review of clinical and laboratory findings and treatment of tumor lysis syndrome. Clin Chim Acta. 2003;333(1):13-18.

21. Davidson MB, Thakkar S, Hix JK, Bhandarkar ND, Wong A, Schreiber MJ. Pathophysiology, clinical consequences, and treatment of tumor lysis syndrome. Am J Med. 2004;116(8):546-554.

22. Cancernetwork.com [homepage on the Internet]. We Treat Tumor Lysis Syndrome. Cancer Network; 2015. Available from: http://www. cancernetwork.com/review-article/how-we-treat-tumor-lysis-syndrome. Accessed April 22, 2015.

23. Schelling J, Ghandour F, Strickland T, Sedor JR. Management of tumor lysis syndrome with standard continuous arteriovenous hemodialysis: case report and a review of the literature. Ren Fail. 1998;20(4): 635-644.
24. Stapleton FB, Strother DR, Roy S 3rd, Wyatt RJ, McKay CP, Murphy SB Acute renal failure at onset of therapy for advanced stage Burkitt lymphoma and B cell acute lymphoblastic lymphoma. Pediatrics. 1988;82(6):863-869.

25. McCurdy MT, Shanholtz CB. Oncologic emergencies. Crit Care Med. 2012;40(7):2212-2222.

26. Coiffier B, Altman A, Pui CH, Younes A, Cairo MS. Guidelines for the management of pediatric and adult tumor lysis syndrome: an evidencebased review. J Clin Oncol. 2008;26(16):2767-2778.

27. Mirrakhimov AE, Ali AM, Khan M, Barbaryan A. Tumor lysis syndrome in solid tumors: an up to date review of the literature. Rare Tumors. 2014;6(2):5389.

28. Jessica S. Prevention and management of tumor lysis syndrome in adults with malignancy. JAdv Pract Oncol. 2013;4(2):101-106.

29. Mika D, Ahmad S, Guruvayoorappan C. Tumour lysis syndrome: implications for cancer therapy. Asian Pacific J Cancer Prev. 2012; 13(8):3555-3560.

30. McBride A, Peter W. Recognizing and managing the expanded risk of tumor lysis syndrome in hematologic and solid malignancies. J Hematol Oncol. 2012;5:75

31. Mirrakhimov AE, Voore P, Khan M, Ali AM. Tumor lysis syndrome: A clinical review. World J Crit Care Med. 2015;4(2):130-138.

32. Rampello E, Fricia T, Malaguarnera $M$. The management of tumor lysis syndrome. Nat Clin Pract Oncol. 2006;3(8):438-447.

33. Darmon M, Guichard I, Vincent F. Rasburicase and tumor lysis syndrome: lower dosage, consideration of indications, and hyperhydration. J Clin Oncol. 2011;29(3):e67-e68.

34. Bellinghieri G, Santoro D, Savica V. Pharmacological treatment of acute and chronic hyperuricemia in kidney diseased patients. Contrib Nephrol. 2005;147:149-160.

35. Band P, Silverberg D, Henderson J, et al. Xanthine nephropathy in a patient with lymphosarcoma treated with allopurinol. $N$ Engl $J$ Med. 1970;283(7):354-357.

36. LaRosa C, McMullen L, Bakdash S, et al. Acute renal failure from xanthine nephropathy during management of acute leukemia. Pediatr Nephrol. 2007;22(1):132-135.

37. Bosly A, Sonet A, Pinkerton CR, et al. Rasburicase (recombinant urate oxidase) for the management of hyperuricemia in patients with cancer: report of an international compassionate use study. Cancer. 2003; 98(5):1048-1054.

38. Coiffier B, Mounier N, Bologna S, et al; Groupe d'Etude des Lymphomes de l'Adulte Trial on Rasburicase Activity in Adult Lymphoma. Efficacy and safety of rasburicase (recombinant urate oxidase) for the prevention and treatment of hyperuricemia during induction chemotherapy of aggressive non-Hodgkin's lymphoma: results of the GRAAL1 (Groupe d'Etude des Lymphomes de Adulte Trial on Rasburicase Activity in Adult Lymphoma) study. J Clin Oncol. 2003;21(23): 4402-4406.

39. Pui CH, Mahmoud HH, Wiley JM, et al. Recombinant urate oxidase for the prophylaxis or treatment of hyperuricemia in patients With leukemia or lymphoma. J Clin Oncol. 2001;19(3):697-704.

40. Givens M, Crandall J. Renal complications in oncologic patients. Hematol Oncol Clin North Am. 2010;24(3):567-575.

41. Conger J, Falk S. Intrarenal dynamics in the pathogenesis and prevention of acute urate nephropathy. J Clin Invest. 1977;59(5):786-793.

42. Agha-Razii M, Amyot SL, Pichette V, Cardinal J, Ouimet D, Leblanc M. Continuous veno-venous hemodiafiltration for the treatment of spontaneous tumor lysis syndrome complicated by acute renal failure and severe hyperuricemia. Clin Nephrol. 2000;54(1):59-63.

43. Choi KA, Lee JE, Kim YG, et al. Efficacy of continuous venovenous hemofiltration with chemotherapy in patients with Burkitt lymphoma and leukemia at high risk of tumor lysis syndrome. Ann Hematol. 2009;88(7):639-645. 
Open Access Emergency Medicine

Dovepress

\section{Publish your work in this journal}

Open Access Emergency Medicine is an international, peer-reviewed, open access journal publishing original research, reports, editorials,

Visit http://www.dovepress.com/testimonials.php to read real quotes reviews and commentaries on all aspects of emergency medicine. The manuscript management system is completely online and includes a very quick and fair peer-review system, which is all easy to use. from published authors.

Submit your manuscript here: http://www.dovepress.com/open-access-emergency-medicine-journal 